\title{
Desejo 24/7: design e consumo
}

\section{Desire 24/7: design and consumption}

ZENOBIO DE ASSUMPÇÃO VILLAR LAUFHÜTTE, Maria Luiza; Estudante de doutorado; Pontifícia Universidade Católica do Rio de Janeiro

lullyvillar@hotmail.com

CIPINIUK, Alberto; Prof. Dr.; Pontifícia Universidade Católica do Rio de Janeiro

acipiniuk@gmail.com

\section{Resumo}

O objetivo desse artigo é a relação entre o design e a ubiquidade da prática ininterrupta do consumo dos objetos. Quem de fato produz o "desejo" por esse ou por aquele objeto? De acordo com a vertente teórica que empregamos, o Campo do Design ${ }^{1}$ inicia a sua constituição a datar da segunda metade do século XVIII, mais precisamente a partir da Revolução Industrial. Consequentemente, a sociedade de consumo se desenvolveu, principalmente, também com a Revolução Industrial e a mecanização da indústria. Logo, pensaríamos em como consumir os objetos, transformados em mercadorias, continuamente em um sistema $24 / 7$, influenciados e controlados, inclusive, através dos meios de comunicação como a televisão e o cinema.

Palavras Chave: design; consumo; desejo.

\begin{abstract}
The goal of this paper is the relation between the design and the omnipresence of the uninterrupted practice of the consumption of objects. Who actually produces the "desire" for this or that object? According to the theoretical section that we use, the Field of Design begins its constitution dating to the second half of the eighteenth century, more precisely from the Industrial Revolution. Consequently, the consumer society developed mainly with the Industrial Revolution and the mechanization of industry. Soon, we would think of how to consume objects, transformed into commodities, continuously in a 24/7 system, influenced and controlled, including through the media such as television and movies.
\end{abstract}

Keywords: design; consumption; desire.

\footnotetext{
${ }^{1}$ Campo do Design, Campo do Cinema ou Campo do Teatro são termos técnicos formulados por Pierre Bourdieu (1983: 44 - 45) e por essa razão grafados em letra maiúscula.
} 


\section{O design e o desenvolvimento da sociedade do consumo}

Primeiramente, gostaríamos de esclarecer que o termo design envolve duas dimensões e que muitas vezes são confundidas: design, como forma ou configuração e design como processo ou prática. Em inglês o termo significa a mesma coisa, mas como uma língua é também uma cultura, eles, os anglófonos, sabem por meio de outras associações, diferenciar um sentido do outro. Nós, muitas vezes, ainda não sabemos e isso é percebido entre os pares dentro do próprio Campo do Design no Brasil, não havendo até hoje um consenso geral sobre o que é isso que é o design, isto é, se estamos tratando de uma configuração ou de uma prática.

Adrian Forty (2007, p. 12) em Objetos de desejo relatou que, em relação aos artefatos industriais, a palavra design poderia assumir dois significados principais. O primeiro se referiu à aparência ou à forma dos objetos que era determinada sob julgamentos relacionados às noções de beleza, daí quando afirmamos que tal cadeira possui um "bom design" estamos querendo dizer que ela possui uma bela configuração formal. O segundo sentido foi relacionado à preparação de instruções de racionalização ou planejamento antecipatório para a produção industrial de bens manufaturados, isto é, o primeiro se reportava à dimensão estética e o segundo à dimensão utilitária do objeto industrial. De acordo com esses sentidos ou significados, fica claro que seria um enorme desacerto desmembrá-los, pois a palavra design manifesta, em um sentido mais amplo, que a aparência dos objetos é uma consequência das condições de sua produção, ou seja, que a sua dimensão material não pode ser apartada da sua dimensão simbólica. Não se trata, portanto, de opor uma e outra, mas de entendê-las como complementares.

Paralelamente, um dos aspectos importantes trazidos por Forty em Objetos de desejo, foi a situação histórica onde o design ocorreu pela primeira vez, pois estabelecendo-o como parte integrante do sistema de produção de bens manufaturados originário do sistema capitalista, ficava subentendido que a fabricação de objetos industriais visava o lucro para o fabricante e que o design não possuía unicamente o objetivo de torná-los belos ou funcionais, mas também e sobretudo a produção de mais valia. Forty ressaltou que isso que é o design, portanto, é uma prática social encarregada de criar ou produzir os objetos, principalmente, industriais e também o próprio "desejo" de consumo por tais objetos. Aliás, esse é o título do livro de Forty que, de modo geral, nos perguntou: quem de fato produz o "desejo" por esse ou por aquele objeto? Essa noção se verificou importantíssima para a abordagem sobre o design e para o desenvolvimento desse artigo, pois ficou claro que o modo de produção industrial constrói não apenas o objeto em si mesmo, mas também o desejo da sua aquisição - a sua necessidade -, assim como outras noções simbólicas que o cercam. A noção anterior defendia que o desejo era alguma coisa pessoal subjetiva e independente em cada ser humano. O "meu" desejo não poderia se confundir com o desejo do outro, pois eles eram absolutamente particulares. E o que se verifica agora é que o desejo é algo programando e inculcado sistematicamente pelas mesmas pessoas que produzem os objetos industriais.

Por noções simbólicas entendam-se os processos empregados pelos designers para conquistar o público consumidor por algo ou alguma coisa que tenha ou não tenha valor de uso da maneira como Karl Marx explicou. Tal como, por exemplo, a importante contribuição do design para a construção e legitimação de valor social abstrato, como foi o caso da extrema limpeza descrita por Forty (2007, p. 215). Essa noção simbólica foi construída ou produzida ao mesmo tempo que certos objetos industriais atinentes à higiene pessoal das pessoas e talvez esse seja o mais importante conteúdo do livro Objetos de desejo para pensar o Campo do Design. Aspiradores 
de pó com formas camaleônicas, por exemplo, foram produzidos em profusão a partir de 1920 logo que a indústria percebeu que os mesmos poderiam ser os maiores adversários contra o que as pessoas denominavam ser a sujeira, coisa que abominavam. $\mathrm{O}$ aspirador além de importante é emblemático, pois é a materialização de um arbitrário cultural abstrato, tal como a "limpeza" ou a "higiene". O aspirador se concretiza em um objeto industrial que se apresenta como uma ferramenta para "eliminar" ou sugar para o seu interior a "sujeira" de algum lugar julgado "sujo". Ademais e muito a propósito, a organização (racionalização ou ordenação dos espaços) e a higiene eram consideradas as origens da beleza. Assim, podemos observar que a exaltação à higiene era propagada com extremada força pelo mercado, isto é, pelos produtores industriais de aspiradores de pó e, consequentemente, as donas-de-casa passaram a considerar que era de suma importância não permitirem que o pó se acumulasse em suas casas. A noção demonizada do pó acumulado era uma noção simbólica produzida pelo próprio mercado produtor de produtos de higiene, incluindo o aspirador de pó.

Com o tempo, as casas passaram a ser cada vez mais preenchidas com os objetos que, atualmente, são vendidos aos milhares diariamente. Os teóricos do Campo do Design observaram que os objetos constituem o entorno e o ambiente próprio de cada indivíduo. No último parágrafo de Objetos de desejo, Forty (2007, p. 330) escreveu: "Este livro [...] pretendeu mostrar os modos pelos quais o design transforma ideias sobre o mundo e relações sociais na forma dos objetos". Torna-se óbvio que a prática do design não pode ser compreendida como algo independente, algo em si mesmo e realizado apenas tecnicamente por especialistas do desenho de objetos industriais, mas sim como uma prática social que foi realizada para atender a demandas sociais concretas. Trata-se de uma forma de trabalho, de produção de objetos inserida na sociedade industrial capitalista, tal como Alberto Cipiniuk (2014) a defendeu. Ao entendermos o design revelador do sistema econômico da sociedade industrial, concluímos que o mesmo é também determinado por valores culturais que se emulam a esse modo de produção. Ao mesmo tempo, a demanda do design pode ser entendida como uma prática social que produz peças que operam como um código de distinção social de diferentes grupos da sociedade, conforme veremos adiante.

Observamos que, conforme explicou Gustavo Bomfim² (2014, p. 23-24), o design traduz-se em uma atividade representativa tanto dos objetos de uso como de sistemas de informação materializando, através dos mesmos, os ideais, os arquétipos, as convicções e também as contradições e as incoerências de uma sociedade, incorporando uma porção dos valores e manifestações culturais que a compõe.

A sociedade de consumo evidencia-se primeiramente pelo desejo socialmente construído da posse do que excede o necessário e é frívolo ou mesmo considerado uma mercadoria de luxo. Necessitamos de todos os objetos que possuímos? É produzida uma constante insaciabilidade pela aquisição de algo "novo", enfim, das "novidades", que não é propriamente isso que é o novo como veremos posteriormente, ocasionando no insatisfazível ou insaciável que é preliminarmente satisfeito e logo gera outra "necessidade" como algo automático que se insere em um ciclo inesgotável de consumo.

Se desenvolvida especialmente com a Revolução Industrial, a sociedade de consumo ganha

\footnotetext{
${ }^{2}$ Lembrando que Alberto Cipiniuk, e Gustavo Amarante Bomfim antes do seu prematuro falecimento, assim como Denise Portinari, fazem parte do Laboratório da Representação Sensível do Departamento de Artes e Design da PUCRio, onde nossa pesquisa está sendo desenvolvida.
} 
agilidade maior ao longo do século XIX. Conforme relatado no livro O paraíso do consumo: Émile Zola a magia e os grandes magazines escrito pelo Professor Everardo Rocha do Departamento de Comunicação da PUC-Rio em parceria com outros pesquisadores, durante tal século se estabeleceram os primeiros magazines, famosas lojas de departamentos, nas cidades consideradas importantes e influentes tanto na Europa quanto nos Estados Unidos (Rocha, Frid e Corbo, 2016, p. 43). Consumir passa a significar o desenvolvimento econômico e elemento de mediação das variadas relações que se estabelecem nas sociedades, arrebatadas pelas experiências do consumo e estabelecendo uma estreita relação com os bens adquiridos. Como ter acesso, então, ao consumo de mercadorias de forma ininterrupta?

\section{A violência simbólica e o modelo não social do consumo ininterrupto}

No início do livro 24/7: capitalismo tardio e os fins do sono, Jonathan Crary (2014) expôs que a história oferece exemplos de inovações criadas durante as guerras ou relacionadas às mesmas e que são fatalmente assimiladas pelas sociedades, sendo o soldado sem sono o antecessor do trabalhador ou consumidor também sem sono, o qual seria a última barreira contra o consumo efetivamente ininterrupto. "Produtos contra o sono, quando propagandeados agressivamente por empresas farmacêuticas, se tornariam primeiro uma opção de estilo de vida, e ao fim, para muitos, uma necessidade", descreveu.

Já há algum tempo, explicou Crary (2014), existem mercados 24/7 e infraestrutura para o trabalho e o consumo sem interrupções com as mais variadas instituições pelo mundo. Contudo, ocorre agora a reorganização a criação e a configuração da identidade pessoal e social com o objetivo da adaptação à operação contínua de mercados, redes de informação além de outros sistemas. Complementando, observou o autor que "um ambiente 24/7 parece um mundo social, mas é na verdade um modelo não social de desempenho maquínico e uma interrupção da vida que não revela o custo humano exigido para sustentar sua eficácia".

Crary escreveu esse livro poucos anos após a morte do sociólogo Pierre Bourdieu e se Bourdieu nos alertava para a naturalização da inculcação dos valores sociais ou da cultura por intermédio da violência simbólica, o que temos agora é muito mais profundo e sofisticado. Crary aponta para a ubiquidade ou um controle quase que total disso que é a formação das identidades sociais.

Mas, o que seria essa violência simbólica descrita por Bourdieu e de que forma os pensamentos dele, Forty e Crary se entrelaçam?

Inicialmente, abordaremos a noção de habitus, essa originada na escolástica medieval, e retomada por Bourdieu (1996, p. 144) que a desenvolveu como uma organização de disposições nas nossas formas de pensar, sentir e agir, explicando que o habitus é um corpo socializado, estruturado e que agrega as estruturas imanentes de um universo simbólico ou campo, ou de um setor próprio desse campo, e que também estrutura a percepção e a ação desse mesmo campo. Há um sistema de separações diferenciais nas propriedades dos agentes sociais, ou seja, nas práticas e nos bens simbólicos ou capitais simbólicos que detêm. Continuamente, explicou Bourdieu (1996, p. 19-21), a uma determinada classe, ou determinada "posição" no campo, condiz uma classe de habitus (ou de gostos) produzido pela obediência às regras sociais relacionadas à condição social equivalente e, por intermédio destes habitus e de suas eficiências geradoras, um conjunto contínuo de bens simbólicos e de suas propriedades associadas entre si por uma semelhança de estilo. Finalmente, é concluído que o gosto é construído socialmente. 
Dessa forma, supor que as pessoas fazem suas próprias escolhas parece ingênuo e romântico. O que Bourdieu ensina é que somos precedidos por uma disposição social que se encarrega de nos levar às nossas escolhas e ao que somos, afirmando que não estamos conscientes de que somos determinados por essa mesma disposição social que nos antecede, pois ela é reproduzida por um sutil, mas violento e coercitivo processo de violência simbólica o qual nos leva a acreditar que os valores que temos são naturais e não socialmente constituídos como na realidade são. A violência simbólica é aquela que impõe submissões que nem mesmo são percebidas como violência, pois fundamentam-se nas "expectativas sociais" que são socialmente e sabidamente inculcadas, esclareceu Bourdieu (1996, p. 171).

Sob similar perspectiva de Bourdieu, destacou Crary (2014) como exemplo dessa avassaladora escalada de violência simbólica a história da tecnologia de iluminação descrita pelo historiador e autor alemão Wolfgang Schivelbusch, a qual expôs o grande desenvolvimento da iluminação pública na década de 1880 como causa da redução de temores sobre a escuridão à noite curiosamente associados à expansão da duração e do lucro de variadas atividades econômicas.

A iluminação noturna foi uma demonstração simbólica do que os defensores do capitalismo prometeram ao longo de todo o século XIX: seria a dupla garantia de segurança e de ampliação das possibilidades de prosperar, melhorando para todos, supostamente, o tecido da existência social. (CRARY, 2014)

Sob essa perspectiva, observou Crary (2014), a instauração de um universo 24/7 fornece a acumulação de benefícios e prosperidade, sobretudo, em favor da elite financeira global. Do mesmo modo, sobre a hegemonia da acumulação de capital dessa elite, faz-se interessante analisarmos paralelamente aquilo que Forty (2007, p. 251) descreveu em seu livro: que o alto preço da eletricidade residencial e o custo significativo para conectar uma casa limitava a clientela somente aos mais privilegiados, ou seja, apenas aos mais abastados. Entre 1905 e 1914, citou Forty (2007, p. 253-254), os engenheiros deram grande atenção ao potencial da demanda residencial e seus efeitos no coeficiente de carga. Consequentemente, em 1914 já estava disponível para a compra uma numerosa quantidade de aparelhos elétricos, como fogões, torradeiras, batedeiras e os famosos aspiradores de pó, entre muitos outros objetos eletrificados. Os “cafés-da-manhã elétricos", por exemplo, obtiveram forte publicidade.

Forty (2007, p. 255-256) explicou que devido ao seu alto preço de produção ou geração industrial, a eletricidade deveria conquistar os consumidores através das características dos aparelhos domésticos, pois a venda de energia para a iluminação pública ou para a movimentação das máquinas industriais nas usinas parecia pequena a esse setor industrial. Assim, muitos aparelhos elétricos de uso doméstico, alguns fabricados nos Estados Unidos e outros na GrãBretanha, que empregavam a eletricidade foram projetados. O desenho e a eficiência dos utensílios elétricos tornaram-se foco na divulgação da venda da eletricidade residencial.

Ressaltou Forty (2007, p. 262-265) que por conta da crise financeira e industrial de 1929, foi somente no início da década de 1930 que o preço dos aparelhos eletrodomésticos diminuiu e os fabricantes passaram a investir avidamente na aparência, ou seja, na eficiência simbólica dos mesmos para o consumo de massa. O interesse pelo design "inovador", na verdade produtos apenas epidermicamente diferenciados, e as "novidades" para o lar que inundam nossas casas, deve-se ao início da queda do preço da eletricidade, bastante inacessível à classe trabalhadora até então, e a viabilidade de um mercado de consumo de massa, justificando o investimento no 
mesmo. A indústria norte-americana imprimia a imagem "moderna" exaltando o progresso graças ao uso da eletricidade. Os britânicos, enfim, e praticamente todo o mundo industrializado desse período histórico, visando também grandes lucros, copiaram a ideia.

A década de 1930, também seria caracterizada pela mudança da estética no processo de design com a finalidade de atender à demanda da produção pela indústria (FORTY, 2007, p. 265), ou seja, planejando ou racionalizando os meios de produção para reduzir o custo da mão de obra, assim como no braço comercial do capitalismo ou através do aumento das vendas e com isso mais produção industrial e a realização da mais valia.

Eram atribuídas à eletricidade propriedades simbólicas como ser limpa, moderna e revolucionária, complementou Forty (2007, p. 265), e para expressar tais qualidades, o design "moderno" exaltado pelos americanos baseava-se no estilo Art Déco, cujo início era de luxo para alguns poucos consumidores das elites financeiras, e também nos traços dos carros aerodinâmicos e ambos, sob o nosso ponto de vista, tinham muito mais a ver com uma questão estética do que propriamente utilitária, pois produziam distinção social àqueles que adquiriam produtos desenhados dessa maneira.

Apesar do simbolismo utilizado para expressar modernidade e futuro ter sido modificado no decorrer dos anos, seja na época pesquisada por Schivelbusch ou no início do desenvolvimento dos utensílios domésticos descrito por Forty, sempre foi mantida a intenção de atrair mais consumidores. Conforme, salientou Crary (2014), o nosso planeta é reexaminado enquanto um local de trabalho ininterrupto ou mesmo um "shopping center de escolhas, tarefas, seleções e digressões infinitas, aberto o tempo todo". Dessa forma, explicou o autor, a insônia é a condição para que a produção, a ubiquidade do consumo e do descarte ocorram sem interrupção.

Observando o quadro Arkwright's cotton mills by night pintado pelo artista britânico Joseph Wright of Derby por volta do, vale frisar, ano de 1782, Crary (2014) o entendeu como fonte de antecipação de algumas características das temporalidades $24 / 7$. Além dos prédios de tijolos compostos por seis e sete andares inseridos em uma paisagem rural situada em uma densa floresta, Crary chamou a atenção para a composição da cena noturna iluminada pela lua cheia e para pequenos pontos de luz vindos das janelas dos moinhos de algodão e observou que "a iluminação artificial das fábricas anuncia a instauração racionalizada de uma relação abstrata entre tempo e trabalho, separada das temporalidades cíclicas dos movimentos da Lua e do Sol". Era o prenúncio de uma nova relação entre o tempo, o trabalho e a produção. Logo, pensaríamos em como produzir mais em menos tempo ou mesmo em produções ininterruptas com trabalho, lucro, desejo e consumo 24/7.

Figura: Arkwright's cotton mills by night

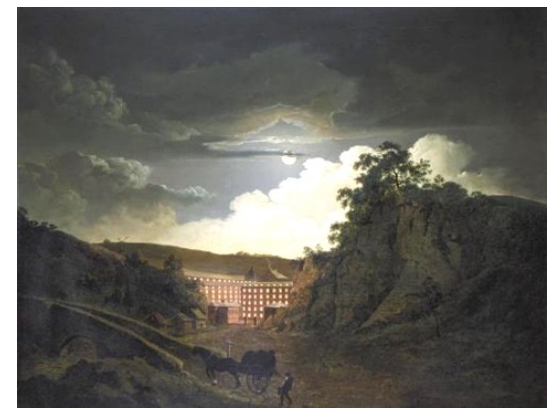

Fonte: Crary, 2014 


\section{0 controle daquilo que é ou não é bom}

Referiu-se Crary (2014) à filósofa alemã Hannah Arendt e seu entendimento sobre a diferenciação entre a esfera privada e a busca individual de felicidade material na qual o sujeito é definido a partir das suas aquisições, por aquilo que consome, alertando para o perigo da ascensão de uma economia na qual "todas as coisas devem ser devoradas e abandonadas quase tão rapidamente quanto surgem no mundo" (ARENDT apud. CRARY, 2014). Escrevendo em meados da década de 1950, Arendt estava ciente não somente de uma sociedade de consumidores impelida por um ciclo perene de coisas que surgem e desaparecem, como também tinha conhecimento de como a vida pública e o trabalho eram experiências que provocavam a alienação na maior parte da população, complementou Crary.

Conforme sublinhado por Crary (2014), a forma assumida pela a inovação no capitalismo é a ilusão permanente do novo, enquanto "as relações de poder e de controle existentes permanecem, na prática, as mesmas". Da mesma forma, observou Forty (2007, p. 20) que a ascensão do capitalismo está inevitavelmente ligada não apenas à produção de objetos industriais, mas à capacidade de "inovar" e vender os produtos. Aliás, compreendemos que inovar, ou o conceito da produção do "novo" com fins comerciais, foi também um produto ou uma tecnologia social produzida pela Revolução Industrial para legitimar a produção de valores ou transformar os antigos valores simbólicos naqueles que interessavam à produção da mais valia.

Ressaltou Forty (2007, p. 265) que após o final da Segunda Guerra Mundial, os eletrodomésticos continuavam a ser os promotores do consumo da eletricidade residencial e deviam continuar transmitindo a imagem da energia mais moderna ainda. Até atualmente, o destaque ao futurismo estético e tecnológico dos aparelhos eletrodomésticos continua sendo ressaltado na promoção da eletricidade. Os produtos elétricos parecem sempre prometer um futuro promissor com tecnologia de ponta e alguma "inovação". Sob a mesma perspectiva sobre o futuro, analisou Crary:

Por boa parte do século XX, a produção de curiosidades, apesar de seu caráter repetitivo e nulo, era frequentemente vendida de maneira a satisfazer a imaginação social de um futuro mais avançado ou pelo menos diferente do presente. No quadro do futurismo de meados do século $X X$, os produtos comprados e incorporados à vida pareciam vagamente relacionados a evocações populares da prosperidade global futura, da substituição benigna do trabalho humano pela automação, da exploração espacial, da erradicação do crime e de doenças e assim por diante. Havia pelo menos a crença equivocada em soluções tecnológicas para problemas sociais insolúveis. Agora, o ritmo acelerado dessas mudanças aparentes elimina o sentimento de padrões temporais compartilhados que poderiam fundamentar a antecipação, ainda que nebulosa, de um futuro diferente da realidade contemporânea. 24/7 é estruturado em torno de objetivos individuais de competitividade, promoção, aquisição, segurança pessoal e conforto à custa dos outros. $O$ futuro está tão à mão que só pode ser imaginado como idêntico à luta pelo ganho ou pela sobrevivência individual no mais superficial dos presentes. (CRARY, 2014)

O filósofo francês Bernard Stiegler, citado por Crary (2014), escreveu sobre as consequências da homogeneização da experiência perceptiva na cultura contemporânea, estando seu foco, principalmente, na circulação global de "objetos temporais" fabricados em massa, entre os quais, segundo descrito por ele, encontram-se filmes, programas de televisão, música popular e videoclipes. Stiegler apontou o alastramento do uso da internet em meados da década de 1990 como um marco decisivo no impacto desses produtos audiovisuais industriais, explicando que nos 
últimos vinte anos os mesmos foram os causadores de uma "sincronização em massa" tanto da consciência quanto da memória. A geração da padronização de experiências sociais em larga escala, afirmou Stiegler, provoca a perda da identidade e da singularidade subjetivas, conduzindo também ao perigoso desaparecimento da participação e da criatividade individuais na constituição dos símbolos que são trocados e compartilhados entre nós. As ideias burguesas ou liberais para organização da sociedade industrial, como se sabe defendiam a liberdade, a legalidade e a igualdade social, contudo a burguesia excluiu o terceiro estado - os proletários - desses direitos, mas continuou afirmando que esses valores permaneciam. Daí talvez a total submissão da responsabilidade em relação à própria vida, complementou Crary (2014), passa a ser apontada através dos títulos dos inúmeros guias que nos dizem quais são "os mil filmes que devemos ver antes de morrer, os cem destinos turísticos que devemos visitar antes de morrer, os quinhentos livros que devemos ler antes de morrer". Em outras palavras, esse mesmo processo foi chamado por Bourdieu de inculcação ou um processo de violência simbólica, conforme descrevemos anteriormente, para reprodução e ampliação de ideias e são os dos agentes sociais com posições de destaque dentro de um campo específico que operam no seu funcionamento decidindo tudo que será ou não inserido no mesmo.

Antes de avançarmos, vamos ao entendimento da posição dos agentes sociais dentro do campo, pois o funcionamento do mesmo está delimitado à dominação dos participantes que determinam o que está dentro e aquilo que "deve" ficar fora do mesmo. O campo, no âmbito desse artigo, é formado pelos agentes da produção composto pelos designers, pelos agentes da recepção constituídos pelo público/consumidores e também pelos agentes de circulação instituídos pelas instâncias de legitimação ou consagração dos objetos definidos como "corretos", interessantes, "inovadores" ou belos.

No que se refere às nossas sociedades modernas, a sociedade de classes, Bourdieu (1996, p. 116) descreveu que o Estado favorece a produção e também a reprodução dos instrumentos de formação da realidade social, estruturando enquanto instância a perpetuação de uma ação geradora de disposições duráveis, através de disciplinas corporais e mentais, e estabelecida no conjunto desses agentes sociais. Portanto, a construção do Estado ocorre paralelamente à constituição de um tipo de histórico comum a todos os agentes sociais daquela estrutura social. $\mathrm{O}$ Estado implanta ou inculca "formas e categorias de percepção e de pensamento comuns, quadros sociais da percepção, da compreensão ou da memória, estruturas mentais, formas estatais de classificação" (BOURDIEU, 1996, p. 116-117). Desse modo, entendemos que a elaboração daquilo que deve ser lido, assistido, visitado ou mesmo consumido é escolhido a partir de outras referências do próprio universo simbólico particular, gerado pelo processo de inculcação, daqueles que nos dizem aquilo que é ou não é bom: os agentes sociais, que também estão, assim como nós, situados em uma determinada estrutura social.

Ao longo do tempo, relatou Crary (2014), os meios sociais como a feira ou o mercado foram sucedidos pelo shopping center, o tempo de lazer foi transformado em mercadoria e foi inventada uma ilimitada sucessão de "caprichos a fim de rebaixar e humilhar os atos simples de compartilhamento por meio dos quais os apetites humanos haviam sido, por muito tempo, atendidos ou satisfeitos", completou o autor. Nos dias de hoje, por exemplo, pode ser incompreensível para um ocidental por qual motivo o vendedor de tapetes em Istambul insiste tanto em "barganhar" a sua venda em lugar de colocar o preço do tapete e o comprador pagar o que está sendo solicitado. 
Crary (2014) citou cronologicamente vários acontecimentos importantes para o desenvolvimento do capitalismo durante os anos. No final da década de 1940 e na década de 1950, a ideia de vida cotidiana era "o conjunto dos hábitos diários pouco notados, onde permanecíamos anônimos". Contudo, lembrou o autor que Henri Lefebvre e Guy Debord, entre outros, relataram nos anos 1950 o avanço da apropriação da vida cotidiana pelo consumo, - do público ou do que era comum a todos, pelo privado - pelo lazer organizado e pelo espetáculo. Sob essa perspectiva, apontou Crary (2014), as ideias do final da década de 1960 foram, pelo menos na Europa e nos Estados Unidos, defendidas a favor da reconquista do cotidiano, da institucionalização e da especialização. Todavia, na década 1980 com o crescimento do neoliberalismo, a comercialização do computador pessoal e a desconstrução de sistemas de proteção social, a vida cotidiana tornou-se mais distante. O próprio tempo foi monetarizado e o sujeito compreendido enquanto um agente econômico em tempo integral.

No final do século XX, continuou Crary (2014), ocorreu uma associação global ou subsunção muito mais completa do sujeito humano ao capitalismo progressivo $24 / 7$. Atualmente, sublinhou o autor, o controle da comunicação, da produção e da circulação de informação, cujas operações são permanentes, entranham em todos os espaços da vida social. Da mesma forma, voltamos ao funcionamento dos agentes sociais da produção, da recepção e da circulação de Bourdieu. Aliás, ressaltamos que seguiram Crary e Bourdieu ainda pela mesma linha de pensamento.

Crary (2014) descreveu a tradição crítica do final do século XIX a qual reconhecia na padronização da experiência uma das qualidades determinantes da modernidade ocidental. À princípio, tal tradição originou-se da ideia da rotinização do lugar de trabalho industrial e as imposições para o cumprimento sem intervalos das ações e tarefas. No início do século XX, houve a expansão do conceito com o objetivo de incluir aspectos cruciais das sociedades de massa emergentes. No decorrer da maior parte do século anterior, todavia, os ambientes de trabalho e de lazer, do público e do privado, haviam mantido, na aparência ou na realidade, alguma diferenciação e separação.

\begin{abstract}
Apesar da rotinização e de hábitos muitas vezes opressores, a vida era para muitos uma tessitura diferenciada de rotinas variadas, entretecidas com pelo menos alguns espaços e tempos não regulados. O hábito, nesse sentido, é uma forma de localizar o comportamento social real em algum lugar entre os extremos imaginados de uma sociedade de indivíduos adormecidos e uma nação mobilizada de indivíduos "despertos". (CRARY, 2014)
\end{abstract}

Crary (2014) frisou que ao debater sobre os séculos XIX e XX, referiu-se aos inúmeros acontecimentos históricos únicos e específicos da mesma forma que aos hábitos que produziram, por exemplo, as diversas estratégias de mecanização e racionalização da atividade em locais de trabalho e a padronização de formas de consumo cultural.

Consideramos, dessa forma, que podemos aproximar a utilização do termo "hábitos" por Crary da noção de habitus retomada por Bourdieu, pois ambos tratam da reprodução e ampliação do senso comum. Crary (2014) foi mais além prevendo que o resultado dessa prática foi o surgimento de formas de hábito que são fatalmente $24 / 7$ e que estão sob o comando dos mecanismos de poder que são identicamente constantes e infindáveis.

No início dos anos 1900, informou Crary (2014), o problema do hábito na modernidade foi tema para diversos filósofos e teóricos sociais que se baseavam na democracia participativa. Citou 
Crary, entre tais filósofos, John Dewey que foi conhecido pela apreensão do confronto entre as formas de comportamento automático e habituais que seguiam a modernidade industrial e a probabilidade da existência de indivíduos dotados de inteligência e com capacidade de reflexão.

Relatou Crary (2014) que o grande conhecimento de Dewey sobre a origem social do hábito era a prova de que o estabelecimento da sociedade ocorria através dos hábitos de que era constituída, sendo esse o motivo pelo qual a reforma da educação fundamental era de grande importância para ele que considerava a possibilidade dos hábitos "inteligentes ou coletivamente benéficos" serem sustentados pela educação.

\title{
40 espectador-consumidor do futuro: televisão e cinema
}

Dewey faleceu em 1952, aos 93 anos de idade, quando a produção de novas formas de hábitos começava a abranger alguns princípios fundamentais do que viria a ser a sociedade de controle 24/7 (CRARY, 2014). Crary (2014) relatou que da mesma forma que a iluminação noturna nas fábricas de Arkwright era uma pista inicial de como seria o futuro com as necessidades do mercado, do mesmo modo a difusão em massa da televisão na década de 1950 é outro momento importante na posse pelo mercado de tempos e espaços não notados anteriormente.

\begin{abstract}
Podemos imaginar, lado a lado, a pintura de Wright, cada uma das janelas da fábrica iluminada pelas lâmpadas a óleo que permitiam o trabalho contínuo, e uma imagem de meados do século XX de um prédio, não muito diferente, com suas janelas iluminadas pelo brilho dos aparelhos de televisão. Em ambos os casos há uma relação de transformação entre o uso de fontes de luz e a construção social do tempo. O tubo de raios catódicos era um exemplo decisivo e vívido de como o brilho e a falação de um mundo público de interações que penetravam mesmo o mais privado dos espaços e contaminavam o silêncio e a solidão que, para Arendt, eram essenciais para a manutenção dos indivíduos políticos. A televisão redefiniu rapidamente o que significava ser membro de uma sociedade. Mesmo a pretensão de valorizar a educação e a participação cívica se esgotou, na medida em que a cidadania era suplantada pela condição de espectador. (CRARY, 2014)
\end{abstract}

Crary (2014) apontou ainda que entre variadas inovações da televisão, os comportamentos homogêneos e habituais eram agora impostos a categorias da vida que estavam anteriormente sob o domínio de meios de controle menos diretos.

\begin{abstract}
Surgida em meio aos efeitos retardados do choque da Segunda Guerra Mundial, a televisão era o local de desestabilização das relações entre exposição e proteção, ação e passividade, sono e vigília, publicidade e privacidade. A necessidade generalizada de uma aparência de continuidade e coesão social após Hiroshima e Auschwitz fez com que a capacidade radicalmente perturbadora da televisão fosse ignorada. Em vez disso, atribuíram-se normalidade e coerência a esse novo mundo televisivo contemplado por todos, em que uma coisa podia ser associada a qualquer outra. Era o antídoto onipresente para o choque. Muito mais decisiva do que o rádio, a televisão foi o local crucial onde foi rapidamente naturalizada a enorme desigualdade de escala entre sistemas globais e as vidas locais e circunscritas dos indivíduos. (CRARY, 2014)
\end{abstract}

Além disso, a televisão produziu condições que seriam posteriormente primordiais para a "economia da atenção" $24 / 7$ do século XXI. E anterior à televisão, na opinião de Crary, a reorganização do tempo e da atividade humanos podia ser pouco comparada historicamente. Para o autor, mesmo o cinema e o rádio eram somente antecipações parciais das alterações estruturais introduzidas pela televisão. "No intervalo de menos de quinze anos, populações inteiras foram colocadas em um estado prolongado de relativa imobilidade", descreveu Crary (2014). Milhões de 
indivíduos rapidamente passaram a ficar prolongadas horas, fosse dia ou noite, sentados diante dos tais aparelhos iluminados.

Apesar de Crary ter associado a televisão ao principal meio de comunicação da sociedade, pelo menos do século $X X$, compreendemos que o cinema já teria influenciado os hábitos de milhões de espectadores anteriormente nas décadas de 1920 e 1930.

O sociólogo não foi o único, nem tampouco o primeiro a afirmar, mas de acordo com o nosso recorte teórico, faz-se importante mencionarmos que Bourdieu (1996, p. 15) explicou que todo o seu empreendimento científico se baseou na certeza de que não é possível compreender a lógica do mundo social se não for analisada uma realidade empírica, localizada e datada historicamente. "É preciso perguntar-se quais são as condições históricas", completou o autor (1996, p. 17). Portanto, as condições históricas concretas consistem na primeira condição para uma tomada de posição apropriada da observação da relação entre as diferentes posições sociais, as disposições (ou os habitus) e as tomadas de posição dos agentes sociais, concluiu Bourdieu (1996, p. 18). Assim sendo, entendemos que é necessário a abordagem da visibilidade do cinema no início do século XX e os também incontáveis espectadores que frequentavam as sessões diárias. É certo que Crary expôs que a televisão tinha (e tem) a capacidade de estar diariamente nas nossas vidas privadas. Mas, é preciso pensarmos em primeiro lugar no cinema nas décadas de 1920 e 1930, quando era ele quem influenciava o habitus de toda uma população.

O motivo do argumento de Crary deveu-se ao fato da televisão ter sido transformada em instrumento de regulação, gerando efeitos de sujeição e supervisão nunca vistos antes. Por esse motivo Crary (2014) considerou a televisão parte fundamental e adaptável de uma longa transição, que demorou anos, "de um mundo de instituições disciplinares mais antigas a um mundo de controle 24/7". Crary explicou ser possível demonstrar que nas décadas de 1950 e 1960 a televisão introduziu nas residências artifícios disciplinares elaborados em contextos diferentes. A televisão tem um efeito sedentarizante aos indivíduos que permanecem estáticos em seus lugares e, conforme citou Crary, "esvaziados de eficácia política". Apesar da ação de assistir à televisão não requerer trabalho físico, Crary a descreve como "um arranjo no qual a administração dos indivíduos coincide com a produção de valor excedente, uma vez que a nova acumulação foi impulsionada pelo tamanho da audiência".

Assim como Crary, Bourdieu (1997) descreveu ao longo de Sobre a televisão de que forma esse poderia ser um instrumento com a capacidade de abranger o mundo inteiro. Pensamos que o mesmo, e muito anteriormente conforme já defendemos, ocorreu em relação ao cinema, principalmente, no que diz respeito ao cinema norte-americano e à sua popularização e demonstraremos que as ideias expostas por ambos os escritores se adequam ao nosso artigo.

Recorremos ao livro Hollywood beyond the screen: design and material culture no qual descreveu Anne Massey (2000, p. 11) que desde o início do segundo decênio do século XX, fãs de filmes de Hollywood iam ao cinema, pelo menos, duas vezes por semana e várias mulheres, inclusive de outros países copiavam as roupas e os penteados das atrizes americanas. Destarte, primeiramente, consideramos tanto a televisão quanto o cinema instrumentos utilizados pelos agentes de produção e circulação daquilo que deve ser visto e aplaudido pela audiência.

Sob outra perspectiva, Bourdieu (1997, p. 19-22) analisou as pressões econômicas exercidas sobre a televisão. Não é justificável pensarmos que o que é transmitido pela televisão é definido por aqueles que a possuem, pelos anunciantes pagantes dos comerciais de publicidade 
ou mesmo pelo Estado provedor de financiamentos. Ocorre que a própria crítica oculta os mecanismos camuflados com os quais são exercidas as censuras determinantes para que a televisão seja um meio extraordinário da conservação e reprodução da ordem simbólica. Perguntamo-nos então: não estaria o Campo do Cinema sob a prática dessa mesma censura a qual limita a veiculação de diversos filmes? Mais uma vez, voltamos aos agentes de produção e circulação, os quais são manipulados e manipuladores desses meios de comunicação, envolvidos muitas vezes por cifras milionárias de produções exorbitantes que mascaram os artifícios dos sedutores mercados televisivo e cinematográfico, assim como também ocorre com a prática do design.

“Desejaria, então, desmontar uma série de mecanismos que fazem com que a televisão exerça uma forma particularmente perniciosa de violência simbólica", relatou Bourdieu (1997, p. 23). A violência simbólica opera nas relações sociais e, especialmente, nas relações de comunicação através do produto audiovisual. Trazemos como debate, o fato de que muito antes da televisão, os filmes tornaram-se uma das mais poderosas maneiras de formar isso que chamamos de opinião pública - o hegemônico, o main stream, as "verdades" que todos falam e reproduzem -, maneira coercitiva própria da violência simbólica, ou seja, um processo opressor de inculcação de valores e crenças. Conforme expomos, a teoria da violência simbólica baseia-se em uma teoria da geração da crença da socialização fundamental para a produção dos agentes dotados das características de percepção e avaliação e, no caso desse artigo, os agentes de produção e circulação que criam discursos para legitimar ou consagrar um filme, um cenário ou até mesmo um único objeto. Se Bourdieu (1997, p. 23) observou que "a televisão tem uma espécie de monopólio de fato sobre a formação das cabeças de uma parcela muito importante da população", consideramos que o cinema já exercia também tal função.

A forma de representação hegemônica nos dias de hoje e que se emula com o texto escrito, é a imagem que podemos ver todos os dias e praticamente o tempo todo, nas telas de televisão. Ela se caracteriza por exibir o chamado por críticos literários de "o efeito de real", fazendo crer no que se faz ver, constituindo ideias, representações e grupos e produzindo infindáveis resultados. Ao representar variedades, acidentes cotidianos, fatos políticos ou novelas, a imagem televisiva tem a capacidade de suscitar intensos sentimentos contra ou a favor de determinados assuntos como, por exemplo, o racismo ou a xenofobia conforme explanou Bourdieu (1997, p. 28-29). Assim, podemos concluir que tanto o emprego da imagem pela TV como o emprego da imagem pelo cinema resulta da mesma forma em uma construção social da realidade, enfim, não se tratando de um mero registro do real. A imagem produzida por ela e que ao mesmo tempo também reproduz comportamentos e gostos de determinados grupos sociais, inseridos nas estruturas sociais, que se identificam ou se distinguem através do uso de determinados objetos, parece ser onipresente. O que está na moda é um arbitrário social e a comprovação de tal veredito efetua-se através do índice de audiência na televisão (BOURDIEU, 1997, p. 38), daí, julgamos que se pode também estendê-lo para o cinema.

Se as diversas emissoras de televisão concorrem entre si pela maior audiência e fatias do mercado segundo expôs Bourdieu (1997, p. 56-58), pensamos a mesma relação de força é estabelecida entre os grandes estúdios cinematográficos, os quais atingem diretamente a estrutura social do campo. Os estúdios interferem nessa estrutura do Campo do Cinema porque acumulam um aglomerado de fatores que influenciam tanto esse universo quanto a própria realidade em que vivem os espectadores. A concorrência através das fatias do mercado 
audiovisual concretiza-se não somente por interesses financeiros, mas, e talvez principalmente, pelo ganho de capital simbólico. Observamos a dominação simbólica do cinema americano, sobretudo de Hollywood, tido como um modelo padrão, um exemplo de ideias, estratégias e processos. Sob a perspectiva dos próprios agentes, o cinema hollywoodiano, certamente, apresenta um enorme peso relativo à quantidade de produções, tornando-se essa uma poderosa característica sob o ponto de vista da distribuição dos filmes. Ou seja, os grandes estúdios obtêm suficiente capital simbólico que os torna soberanos no domínio do campo, produzindo e difundindo tudo aquilo que desejam em uma escala ampla de informação que atinge aos espectadores, mas anteriormente, aos próprios produtores, distribuidores, diretores, roteiristas e demais profissionais envolvidos. Maiormente, "estando em condições de ter acesso permanente à visibilidade pública", indicou Bourdieu (1997, p. 66), todos estes agentes sociais dominados pelos grandes estúdios podem "impor ao conjunto da sociedade seus princípios de visão do mundo" operando na nossa própria realidade. E tais agentes sociais, empregados pelos estúdios e/ou vistos nas telas de cinema, tornam-se ilustres poderosos ou até mesmo, conforme descreveu Bourdieu (1997, p. 54), detentores de "uma aura extraordinária" que ganha ainda mais força através das revistas e matérias sobre os filmes e as estrelas do cinema de Hollywood, ratificando, dessa forma, todo esse complexo de produções simbólicas que contribui imensamente para o gosto, os valores e as preferências do público, tendendo a "despolitizar e reduzir a vida do mundo ao mexerico, a vida das estrelas ou famílias reais", indicou Bourdieu (1997, p. 73), estabelecendo "sentido ao insignificante", completou.

Explicou Bourdieu (1997, p. 77-78) que enquanto agentes sociais temos responsabilidades, contudo somos, em extensa parcela, definidos pelas possibilidades e impossibilidades da estrutura social na qual nos encontramos e pela posição que ocupamos na mesma. Os profissionais de Hollywood enquanto agentes sociais encontram-se, sob esse ponto de vista, como "porta-vozes da emoção popular" ou da "opinião pública". Os filmes enunciam vereditos. Basta pensarmos, por exemplo, nos óculos Ray Ban Wayfarer utilizados pela personagem Holly Golightly interpretada por Audrey Hepburn no filme Bonequinha de luxo ${ }^{3}$ (1961), que simboliza o que passou a ser arbitrariamente consagrado como elegante, exercendo sobre o espectador o desejo da sua aquisição, isto é, do seu consumo.

Para finalizar esse subtítulo, gostaríamos de lembrar que a dominação simbólica não se faz somente pela violência simbólica ou apenas no âmbito do controle de corações e mentes, um fenômeno de superestrutura, mas também pelo controle econômico exercido pelas empresas responsáveis pela circulação dos produtos audiovisuais.

\section{Conclusão}

A era da televisão do pós-guerra acabou em meados da década de 1980, que teve sua capacidade alterada com a disponibilidade do videocassete e a implantação do padrão VHS, consoles de videogames, a TV a cabo comercial e a comercialização do computador pessoal. "No início da década de 1990 esse produto ubíquo anunciaria simbolicamente o advento de uma sociedade de controle depois de uma longa fase de transição", declarou Crary (2014). A década de 1980 é por vezes diversas qualificada como uma época na qual ocorreu um abandono do antigo espectador, o qual tinha o papel de ser meramente receptivo ou passivo da televisão. Houve o surgimento de um "usuário" (CRARY, 2104). Mais criativo ao alcance de maiores recursos de

\footnotetext{
${ }^{3}$ Breakfast at Tiffany's [feature film]. Dir. Blake Edwards. Jurow-Shepherd, 1961. 114 mins.
} 
mídia, esse usuário tem a capacidade de intervir no uso de produtos tecnológicos, passando a obter, no início dos anos 1990, a possibilidade de se relacionar com redes globais de informação. Notemos aqui o uso do termo usuário pelo autor. Enfim, um termo hegemônico entre os pares do Campo do Design para definir quem compra ou adquire um objeto industrial.

As possibilidades de interação dessas novas ferramentas foram vendidas como capacitadoras e intrinsecamente democráticas e anti-hierárquicas - apesar de boa parte da força desse mito ter sido esvaziada desde então. O que era celebrado como interatividade era mais precisamente a mobilização e habituação do indivíduo a um conjunto aberto de tarefas e rotinas, muito além do que era exigido de qualquer pessoa nos anos 1950 e 60. (CRARY, 2014)

O que Crary (2014) chamou a atenção foi para o fato de a televisão ter se juntado aos novos serviços, redes ou aparelhos, modificando perpetuamente suas capacidades e efeitos. Para o autor, a televisão foi somente o primeiro aparelho de toda uma categoria que atualmente está ao nosso redor e que é utilizada na maior parte das vezes de acordo com poderosos padrões de hábito que compreendem atenção difusa e semiautomatismo.

Concomitantemente, Crary (2104) apontou para a mudança em relação ao consumo e à interação dos indivíduos com as mercadorias.

Ainda na década de 1960, a crítica à cultura de consumo identificou as linhas gerais da dissonância entre ambientes saturados de imagens e produtos e o indivíduo que, embora enredado em sua superficialidade e falsidade, percebia ainda que vagamente a discrepância fundamental desses ambientes em relação a seus desejos e necessidades vitais. Consumiam-se sem cessar produtos que inevitavelmente deixavam de cumprir suas promessas originais, ainda que fraudulentas. Agora, no entanto, a existência de uma divergência entre o mundo humano e o funcionamento de sistemas globais capazes de ocupar cada hora de vigília de nossas vidas parece uma ideia datada e impertinente. Há muita pressão para que os indivíduos reimaginem e reconfigurem-se a si mesmos, identificando-se com as uniformidades e valores das mercadorias, bem como dos vínculos sociais desmaterializados nos quais estão tão profundamente imersos. (CRARY, 2014)

Observou Crary (2014) a experiência de reificação e, consequentemente, a influência das mudanças tecnológicas, da criação de novas tecnologias de informação e comunicação e da disseminação dos dispositivos móveis nas relações entre o Estado e a sociedade, trazendo para a finalização do debate duas obras relacionadas: o romance $O$ caçador de androides de Philip K. Dick da década de 1960 e o filme Blade Runner dirigido por Ridley Scott nos anos 1980. Crary pretendeu mostrar as relações sociais sujeitadas e relacionadas cada vez mais ao caráter inanimado, quantitativo e automático dos objetos ou mercadorias à venda no mercado.

O caçador de androides abre espaço para algo muito diferente na versão cinematográfica. A descrição, no romance, da destruição ininterrupta e mesquinha da experiência individual é transformada em uma celebração desenganada da petrificação e da "abstração maligna" frente à qual Dick recuou. Lançado durante os primeiros anos da era Reagan-Thatcher, Blade Runner é um esboço da reconfiguração da cultura de consumo global emergente que se estabeleceria mais solidamente nos anos 1990 . Em vez de rastrear a cisão entre o eu e seu meio, o filme afirma a assimilação funcional do indivíduo aos circuitos e mecanismos de um campo expandido de mercantilização. Torna emocionalmente confiável o limiar sombrio no qual os produtos tecnológicos das corporações se convertem em objetos de nossos desejos, de nossas esperanças. (CRARY, 2014)

E como que em um ciclo vicioso da produção de mais valia e do consumo acelerado, Crary 
se une novamente aos pensamentos de Forty, fazendo-nos pensar mais uma vez nos objetos dos nossos desejos ou convertidos em nossas mais irreais necessidades. $O$ mundo da fantasia ou o mundo da arte não tem mais como se distinguir do mundo real.

Talvez, uma das mais importantes declarações de Blade Runner ocorra na cena entre Deckard e Roy, quando o Deckard revela ao replicamte: "você foi criado da melhor maneira possível, mas não para durar". É a sentença de morte daquele produto, de mais uma mercadoria com os dias contatos para ser qualificada como ultrapassada.

Vivemos em um mundo manipulado. Trata-se do tal processo de inculcação no qual é instaurado o desejo 24/7. Ao longo da transferência das relações sociais a formas monetizadas e quantificáveis, chegamos às nossas mais profundas dependências dos objetos. Sempre desejamos mais. Descreveu Crary (2014) que durante todo o século XX, acreditava-se que os desejos estivessem associados apenas a necessidades individuais, como "desejar a casa dos sonhos, 0 carro dos sonhos ou férias". Perguntamo-nos se algo mudou agora no século XXI?

\section{Referências}

BOMFIM, Gustavo Amarante. Coordenadas cronológicas e cosmológicas como espaço das transformações formais. In.: COUTO, Rita Maria de Souza et OLIVEIRA, Alfredo Jefferson de. Formas do Design: por uma metodologia interdisciplinar. Rio de Janeiro: 2AB e PUC-Rio, 1999. Reeditado e ampliado por COUTO, Rita Maria, FARBIAZ, Jackeline Lima, NOVAES, OLIVEIRA, Alfredo Jefferson, organizadores. Rio de Janeiro: Rio Book's, 2014.

BOURDIEU, Pierre. Razões práticas. Campinas: Papirus, 1996.

Sobre a televisão. Rio de Janeiro: Jorge Zahar, 1997.

CIPINIUK, Alberto. A ideologia comercial do século XVII e a transição dos estilos. In.: COUTO, Rita Maria de Souza et OLIVEIRA, Alfredo Jefferson de. Formas do Design: por uma metodologia interdisciplinar. Rio de Janeiro: 2AB e PUC-Rio, 1999. Reeditado e ampliado por COUTO, Rita Maria, FARBIAZ, Jackeline Lima, NOVAES, OLIVEIRA, Alfredo Jefferson, organizadores. Rio de Janeiro: Rio Book's, 2014.

CRARY, Jonathan. 24/7: capitalismo tardio e os fins do sono. São Paulo: Cosac Naify, 2014.

FORTY, Adrian. Objetos de desejo. São Paulo: Cosac Naify, 2007.

MARX, Karl. Manuscritos econômicos-filosóficos e outros textos escolhidos. Seleção de José Arthur Giannotti. São Paulo: Abril Cultural, 1978.

MASSEY, Anne. Hollywood beyond the screen: design and material culture. Oxford; New York: Berg, 2000.

ROCHA, E.; FRID, M.; CORBO, W. O paraíso do consumo: Émile Zola, a magia e os grandes magazines. Rio de Janeiro: Mauad X, 2016. 